\title{
Rosenbaum, L. (2014). Not Exactly As Planned: A Memoir of Adoption, Secrets and Abiding Love. Bradford, Ontario: Demeter Press.
}

Reviewed by Angela Felgate, MacEwan University.

Linda Rosenbaum's book, "Not Exactly as Planned", is a memoir about the secrets held within her family and the journey of adopting and raising her son with fetal alcohol syndrome. Rosenbaum discusses this recurring idea of secrets within her family from an early age when she first learns the truth of her grandmother and her battles with mental health. This is far from the only secret she has within her family, which grow to include the incident in Washington and the truth about her adopted son Michael's biological family. Rosenbaum steps on the topic of mental health when she discovers that her grandmother had been living in a mental institution, and this topic continues to appear throughout Rosenbaum's life when she herself begins to suffer from mental health issues.

Another struggle Rosenbaum faces in her memoir is the struggle to adopt with her husband, Robin. When they finally are able to get their baby boy, they are left to face many obstacles as their son suffers from fetal alcohol syndrome; a diagnosis they wait on for years. While Rosenbaum and her husband were left to believe adopting one baby at their age may be impossible, by some chance they come across the opportunity of another baby, welcoming their baby girl Sarah.

At the young age of ten, Rosenbaum answered a phone call that would bring her shock as well as a vow to herself that she would never keep secrets. While she had believed that her grandmother had been dead for years, she learned over the phone that in reality she had been alive 


\section{Felgate}

and living in a mental institute for years. The anger and hurt Rosenbaum felt after being lied to by her own mother made her desire to always be open and honest with the people she loved. However, she would learn through her life that these promises would be much harder than she ever thought. Just before Rosenbaum's university graduation in Washington, DC, she and her roomate, Rosie, suffered through a sexual assault that would change the trajectory of their lives. After the incident, Rosenbaum returned back home to heal, and although promised never to keep secrets from her family, decided that this incident would be the exception as she only confided in her sister and her close friend. Even though she knew this was a big and dark secret, and something she "promised as a child [she] never would do... [she] was protecting [herself] from what other people, including the people [she] loved, might think, say or feel" (p. 37). Rosenbaum began to understand the reasons one may keep secrets, and this would be only the first major secret she would have within her family.

Rosenbaum first brings up mental illness when she discovers at ten years old that her grandmother must have dealt with some mental health issues. Rosenbaum herself shows to have some struggles with mental health and it is first brought up whilst she experiences a panic attack on an airplane on Christmas Day. Her panic attack is caused by seeing engines on the planes wing on fire, triggering feelings of being trapped or unable to escape. After going to see a therapist to help deal with her anxiety, she is forced to relive the memory of what happened to her in Washington. This was done over the course of a year where she was claustrophobic, felt trapped, was physically and mentally drained, and lost over forty pounds. She also began taking Valium to 


\section{Felgate}

help get her through the day whilst her panic attacks were occurring. She had experienced very dark days and feelings of anger, fear, and powerlessness arose from the incident in Washington. Finally after a year on anti-depressants she began to become more stable and was able to start thinking about her future again.

Rosenbaum had met her husband through an ad her and her friend put in the paper to attract men between the ages of 30 and 45 to start a French conversation group. Soon after they had married, they wanted to embark on starting a family, however, Rosenbaum struggled with infertility and was unable to conceive. This led them through the process of adoption. Being told that at their age it would likely be very hard to adopt or it could take years, they were advised to try and find a child on their own somehow who which they could adopt. Despite being unsure of how they would be able to find their own baby, the opportunity seemed to fall in their lap. Another important phone call that would change the rest of her life came from her neighbor Lynn, who's husbands daughter, Kira, was pregnant. She was wanting to give up her baby for adoption, and after going back and forth, Rosenbaum decided that this boy would be hers.

While Rosenbaum was very happy to fulfill her lifelong dream of becoming a mother, she had concerns right from the beginning about her baby boy Michael. He would not settle long; thrashing in his cradle and crying constantly. He seemed tiny and frail, but despite frequent trips to the pediatrician, they always ended with them being told that he is fine and he will grow out of it. However, that was not the case. After years of struggling to try and understand Michaels behaviour, trying different strategies that would help him, and Rosenbaum and her husband feeling like unfit parents, they finally got an answer. At age six, Michael was diagnosed with fetal alcohol 


\section{Felgate}

syndrome. A diagnosis that would give them an answer and an understanding to all the difficulties they faced in the years prior. Along with his fetal alcohol syndrome, Michael also was shown to have autistic characteristics that showed in his interactions with other children and his tendency to parallel play. Despite Michael's preference to play on his own, there was one other boy that was the exception. Andrew, who had also been the son of Michael's birth mother, Kira, was adopted by Rosenbaum neighbor's, which were Kira's father and step mother. Due to Kira's inability to raise Andrew, he was given to her father and his wife. This meant that Andrew would be living next to his half-brother Michael, and the two would not be able to know of their relationship. Due to the adoption process Rosenbaum went through, the identity of Michael's birth mother was meant to be kept secret as she would have no involvement where he went or his life. This, again, was another secret Rosenbaum knew she would have to keep, despite her vow to always be honest with her family made years earlier.

Interestingly enough, just as Rosenbaum met Robin through an ad she posted in the paper, her and Robin came to adopt their daughter Sarah by doing just the same thing. Despite the difficulties they were having in raising Michael, the two loved to be parents and wanted to have another child. Although they were told years earlier, before adopting Michael, that they may never be able to, they took their chances again and posted an ad in the paper looking for another baby to welcome into their family. As fate would have it, Rosenbaum received another life changing phone call from a woman named Denise who was looking for a loving family in which to give her baby to. Through this, Rosenbaum and her husband would welcome their baby daughter "Sarah Christmas... born on Christmas Day" (p. 123). 
Felgate

Rosenbaum's intentions in writing this memoir is to show the uniqueness of her story, and despite struggles through secrets, mental health, adoption, and a difficult diagnosis, her family was able to persevere and come together through it all. This memoir held many different aspects of Rosenbaum's life and highlighted some of the highest and lowest points of her life that I believe many people facing issues such as sexual abuse or parents looking to adopt could benefit greatly from. It shows that despite challenges and consequences, it is possible to get through and have a positive future. I found "Not Exactly as Planned" a pleasure to read and exciting as she walked through the not so smooth journey of her life. I would recommend it to anyone who is interested in social work or fields studying family and adoption. 